Arq. Bras. Med. Vet. Zootec., v.62, n.2, p.293-301, 2010

\title{
Morfologia e histologia do oviduto de marrecas Ana boschas
}

\author{
[Morphology and histology of Ana Boschas female ducks oviduct] \\ C. Moraes, S.M. Baraldi-Artoni*, M.R. Pacheco, M. Nishizawa, L.S.O. Nakaghi \\ Faculdade de Ciências Agrárias e Veterinárias - UNESP \\ Via de Acesso Prof. Paulo Donato Castellane, s/n \\ 14884-900 - Jaboticabal, SP
}

\begin{abstract}
RESUMO
Avaliaram-se o comprimento do infundíbulo, do magno, do istmo, do útero e da vagina e o número de pregas do magno e do istmo do oviduto de 20 marrecas Ana boschas na fase reprodutiva. O infundíbulo apresenta mucosa com pregas longitudinais e baixas, revestidas por epitélio pseudoestratificado cilíndrico ciliado, com células caliciformes. O magno, compartimento mais longo do oviduto, 25,38cm $\pm 3,20$, encontra-se constituído por uma camada mucosa com pregas altas e espessas revestidas por células cilíndricas ciliadas e abundantes células caliciformes. $\mathrm{O}$ istmo é formado por uma mucosa com pregas estreitas e curtas e numerosas glândulas tubulares que se estendem para o interior da lâmina própria. O útero, região curta do oviduto, $5,25 \mathrm{~cm} \pm 1,26$, apresenta parede com pregas e cristas baixas e numerosas glândulas tubulares enoveladas, dirigidas para o interior da lâmina própria. A vagina, um estreito tubo muscular, está constituído por oito anéis circulares, em média, e uma camada muscular altamente desenvolvida e espessa. A morfologia do oviduto da marreca apresenta características morfológicas e histológicas distintas dos galiniformes, observando-se que a vagina e a porção cranial do infundíbulo apresentam pregas e células caliciformes, respectivamente, sendo estas últimas estruturas ausentes nos galiniformes.
\end{abstract}

Palavras-chave: marreca, morfologia, histologia, sistema reprodutor

\begin{abstract}
The length of infundibulum, magnum, isthmus, uterus, vagina, and the number of oviduct, magnum, and isthmus folds were evaluated in 20 Ana boschas female ducks in the reproductive phase. The infundibulum presented mucous membrane with longitudinal and short folds, covered by ciliated columnar pseudostratified epithelium, with goblet cells. Magnum, the longest oviduct compartment, $25.38 \mathrm{~cm} \pm 3.20$, is constituted by mucous membrane with high and thick folds that are covered by ciliated columnar cells and many goblet cells. Isthmus is formed by mucous membrane with narrow and short folds, and many tubular glands that extend inside lamina propria. Uterus, an oviduct short region, $5.25 \mathrm{~cm} \pm 1.26$, presented surface with short folds and crests, and numerous reeled tubular glands, that are directed inside lamina propria. Vagina, a strait muscular tube, is constituted by, approximately, eight circular rings, and a very developed and thick muscular layer. The oviduct morphology of female ducks presented different morphological and histological characteristics from Galliformes, because vagina and infundibulum cranial portion present folds and goblet cells, respectively, and the last cited structures are absent in Galliformes.
\end{abstract}

Keywords: female duck, morphology, histology, reproductive system

\section{INTRODUÇÃO}

Anatidae é uma família de aves que tem como representantes os cisnes, marrecos e patos. Em comparação com regiões de climas mais temperados, o Brasil não é muito rico em
Anatidae. O Rio Grande do Sul é o estado com maior diversidade, com 21 espécies classificadas (Sick, 2001).

A reprodução de marrecos é marcada por cerimônias pré-nupciais bem variadas, cuja

Recebido em 25 de novembro de 2009

Aceito em 31 de março de 2010

* Autor para correspondência (corresponding author)

E-mail: smbart@fcav.unesp.br 
análise aponta o parentesco de certos grupos de espécies e gêneros dentro da família. Geralmente são monógamos e os machos tornam-se ciosos de suas fêmeas, durante a reprodução (Sick, 2001). Sisson e Grossman (1986) e Dyce (1996) relataram que os órgãos reprodutores de fêmea de aves são constituídos pelo ovário e oviduto. $\mathrm{O}$ ovário produz o óvulo, sendo que a gema é fabricada no interior do oócito a partir de matéria-prima sintetizada pelo fígado, e os demais constituintes, tais como o albúmen, as duas membranas da casca e a casca, são sintetizados no próprio oviduto.

Nas aves domésticas, na embriogênese, são formados dois ovários e dois ovidutos. Após o nascimento, há regressão do oviduto direito e apenas o esquerdo se desenvolve (Gilbert, 1979). Aitken (1971), Gilbert (1979), Ribeiro et al. (1995), Dyce (1996) e Sultana et al. (2003) relataram que o oviduto pode ser dividido anatomicamente em cinco regiões distintas e com funções fisiológicas específicas: infundíbulo, magno (região secretora de albúmen), istmo, útero (glândula da casca) e vagina.

Em aves comerciais, observou-se que o infundíbulo consiste de um funil seguido por uma região tubular. $\mathrm{O}$ infundíbulo secreta material proteico depositado ao redor da gema e contribui para a resistência da membrana prévitelina, segundo Sisson e Grossman (1986) e Hafez (1988). Gilbert (1972) descreveu que o magno é a região secretora de albúmen e a mais longa que qualquer outra no sistema reprodutor, e distingue-se do infundíbulo e do istmo por seu diâmetro externo maior e suas paredes mais espessas. As dobras da mucosa são grandes e amplas e mais numerosas do que em qualquer outra parte do oviduto. As pregas presentes no magno são as mais altas e mais espessas (Wyburn et al., 1970). O istmo, região curta do oviduto, de diâmetro reduzido e situado entre o magno e a glândula da casca, apresenta faixa estreita de tecido (zona translúcida) na qual as glândulas tubulares estão ausentes e sua parede é mais fina quando comparada às demais partes do oviduto (Giesberg, 1922).

O útero é uma região expandida, curta e semelhante a um saco (Sisson e Grossman, 1986). Giersberg (1922) relatou que a parede é espessa e com uma camada muscular bem desenvolvida. Johnston et al. (1963) distinguiram uma porção cranial curta e relativamente estreita, através da qual o ovo provavelmente passa rapidamente, e uma porção caudal semelhante a uma bolsa (parte maior do útero) que mantém o ovo durante a maior parte do período de formação da casca.

A vagina é um estreito tubo muscular, acentuadamente curvo, e com uma mucosa branca (Fujii e Tamura, 1963). Sua junção ao útero é demarcada por um forte esfíncter. Suas pregas são longitudinais ao invés de espiraladas e bem mais delgadas e mais baixas do que em qualquer outra parte do oviduto, exceto no funil do infundíbulo. Na região do esfíncter da vagina, as pregas são especialmente modificadas, tornando-se menos uniformes e apresentando superfícies que são de aparência ásperas; onde o esfíncter estreita o lúmen, observa-se que as pregas estão intimamente juntas, desta forma, reduzindo o lúmen a um estreito anel (Bobr et al., 1964).

Neste sentido, o presente trabalho teve o objetivo de analisar a morfologia e a histologia do oviduto de marrecas Ana boscha.

\section{MATERIAL E MÉTODOS}

Esta pesquisa foi aprovada pelo Comitê de Ética e Bem Estar Animal (CEBEA) da Faculdade de Ciências Agrárias e Veterinárias, Campus de Jaboticabal. Protocolo n ${ }^{\circ}$ 024762/09.

Foram utilizadas 20 marrecas adultas em fase de reprodução, com peso médio de $1600 \mathrm{~g}$. As aves foram anestesiadas com éter etílico por inalação e sacrificadas por deslocamento cervical. Após a laparotomia e o rebatimento do esterno caudocranial, os ovidutos de 10 aves foram retirados, pesados e imersos em uma solução de formol a $10 \%$ para a realização do estudo morfológico. Posteriormente, em sequência mediu-se infundíbulo, magno, istmo, útero $\mathrm{e}$ vagina e contou-se o número de pregas do magno e do istmo.

Para o estudo histológico, coletaram-se amostras de $5 \mathrm{~cm}$ do infundíbulo, magno, istmo, útero e da vagina de 10 marrecas as quais foram imersas em solução de Bouin, por 24 horas. Posteriormente, banhos sucessivos de álcool $70 \%$ foram aplicados sobre as amostras, para a retirada do fixador, e em seguida estas foram desidratadas 
em uma série de concentração crescente de álcoois (80, 90, 95 e 3x 100\%). Após a desidratação do material, as amostras foram recortadas em fragmentos de $0,5 \mathrm{~cm}$ de comprimento por $0,5 \mathrm{~cm}$ de largura, diafanizadas em xilol e incluídas em parafina, visando à obtenção de cortes histológicos de $7 \mu \mathrm{m}$ de espessura que foram corados com hematoxilinaeosina e, posteriormente, analisados e fotomicrografados com $\mathrm{O}$ auxílio de um fotomicroscópio Olympus BX-50.

\section{RESULTADOS}

Os órgãos reprodutores da marreca Ana boschas são constituídos pelo ovário e oviduto, sendo este último formado pelo infundíbulo, magno, istmo, útero e vagina. A marreca em atividade reprodutora apresenta o oviduto bem desenvolvido e revelou valores médios de $42,93 \pm 4,67 \mathrm{~g}$ para o peso e $52,5 \pm 4,67 \mathrm{~cm}$ para o comprimento.

O infundíbulo de marrecas em postura mostrou valores médios de $8 \mathrm{~cm}$ de comprimento e $1 \mathrm{~cm}$ de largura. Apresentou-se em forma de um funil seguido por uma região tubular, sendo que o funil se abriu imediatamente caudal ao ovário. A parede extremamente delgada do funil mostrou uma borda fimbriada na extremidade cranial do oviduto que, segundo a literatura, permite a entrada dos grandes folículos que se encontram suspensos no ovário. A mucosa do infundíbulo evidenciou pregas longitudinais e baixas. $\mathrm{O}$ funil estreitou-se rapidamente para formar a região tubular (colo). A parede desta parte do infundíbulo foi mais espessa do que a do funil, porém mais delgada do que qualquer outra parte do oviduto e apresentou-se rosa-pálido devido à vascularização dessa região (Fig. 1A). As pregas da mucosa formaram uma espiral, as quais foram mais delicadas que as presentes no magno.

Histologicamente, a porção cranial do infundíbulo evidenciou uma mucosa delgada com pregas baixas que estavam revestidas por epitélio pseudoestratificado cilíndrico ciliado, com células caliciformes. Estas últimas estavam intercaladas entre as cilíndricas ciliadas na superfície inferior do epitélio, ou seja, próximas à lâmina basal. Esse epitélio apoiava-se em uma lâmina própria de tecido conjuntivo frouxo, vascularizado (Fig. 2A). A seguir, observou-se uma camada de tecido muscular liso, com fibras cortadas longitudinal, transversal e obliquamente, contínuas à serosa, constituída por tecido conjuntivo frouxo revestido por epitélio simples pavimentoso (mesotélio) (Fig. 2B). Caudalmente, as pregas da mucosa eram mais altas e também estavam recobertas por epitélio pseudoestratificado cilíndrico ciliado, com células caliciformes (Fig. 2C). Esse epitélio sustentava-se sobre uma lâmina própria de tecido conjuntivo frouxo ricamente vascularizado onde se encontravam glândulas tubulares, secretoras de muco (Fig. 2D). As camadas muscular e serosa da porção caudal assemelhavam-se às da região cranial para este segmento do oviduto.

O magno foi o componente mais longo e espiralado do oviduto de uma marreca em postura, 25,38cm. Apresentou mucosa amarelopálido com paredes espessas (Fig. 1B). Mostrou, em média, 16 pregas, as quais eram espiraladas, mais altas e mais espessas do que as pregas observadas nas demais partes do oviduto. O epitélio da mucosa do magno estava formado por células cilíndricas ciliadas com abundantes células caliciformes (Fig. 2E) e apoiava-se em uma lâmina própria formada por tecido conjuntivo frouxo ricamente vascularizado, contendo numerosas glândulas (Fig. 2F). As camadas muscular e serosa foram semelhantes às descritas para o infundíbulo.

$\mathrm{O}$ istmo mediu, em média, $9,25 \mathrm{~cm}$. Entre este segmento e o magno, observou-se tecido aglandular e sem pregas (Fig. 1C). As pregas da mucosa foram mais estreitas e curtas que as observadas no magno (Fig. 1D) e estavam forradas por epitélio pseudoestratificado cilíndrico ciliado, com células caliciformes. Numerosas glândulas tubulares ramificadas estenderam-se para o interior da lâmina própria de tecido conjuntivo frouxo vascularizado (Fig. $3 \mathrm{~A})$. As camadas musculares apresentaram fibras cortadas longitudinal, transversal e obliquamente, contínuas à serosa (Fig. 3B).

O útero apresentou-se expandido, curto, assemelhou-se a um saco e mediu $5,25 \mathrm{~cm}$. Revelou porção cranial curta e estreita, e porção caudal similar a uma bolsa (porção maior do útero) (Fig. 1E). Caudalmente afunilou-se, unindo-se subitamente à vagina. Mostrou mucosa vermelho-amarronzada e intensa irrigação sanguínea no local. A parede do útero era espessa e apresentava camada muscular bem 
desenvolvida, e a mucosa revelava pregas longas e estreitas, revestidas por epitélio pseudoestratificado cilíndrico ciliado, com células caliciformes, apoiado em lâmina própria, que continha, em seu interior, numerosas glândulas tubulares enoveladas (Fig. 3C). As células glandulares possuíam núcleo esférico e centralmente posicionado, enquanto no citoplasma encontraram-se grânulos apicais (Fig. 3D). As porções restantes da parede foram semelhantes às estruturas previamente mencionadas para os segmentos anteriores.
A vagina estava constituída por tecido muscular liso formando túbulo estreito, acentuadamente curvo, e uniu-se ao útero, cuja junção foi demarcada por esfíncter. Sua mucosa, de coloração branco brilhante, evidenciou em média oito anéis circulares (Fig. 1F), pregas baixas delicadas e longitudinais diferentes daquelas observadas em outros segmentos $\mathrm{Na}$ região do esfíncter da vagina, as pregas estavam modificadas, apresentando-se com superfície de aparência áspera.

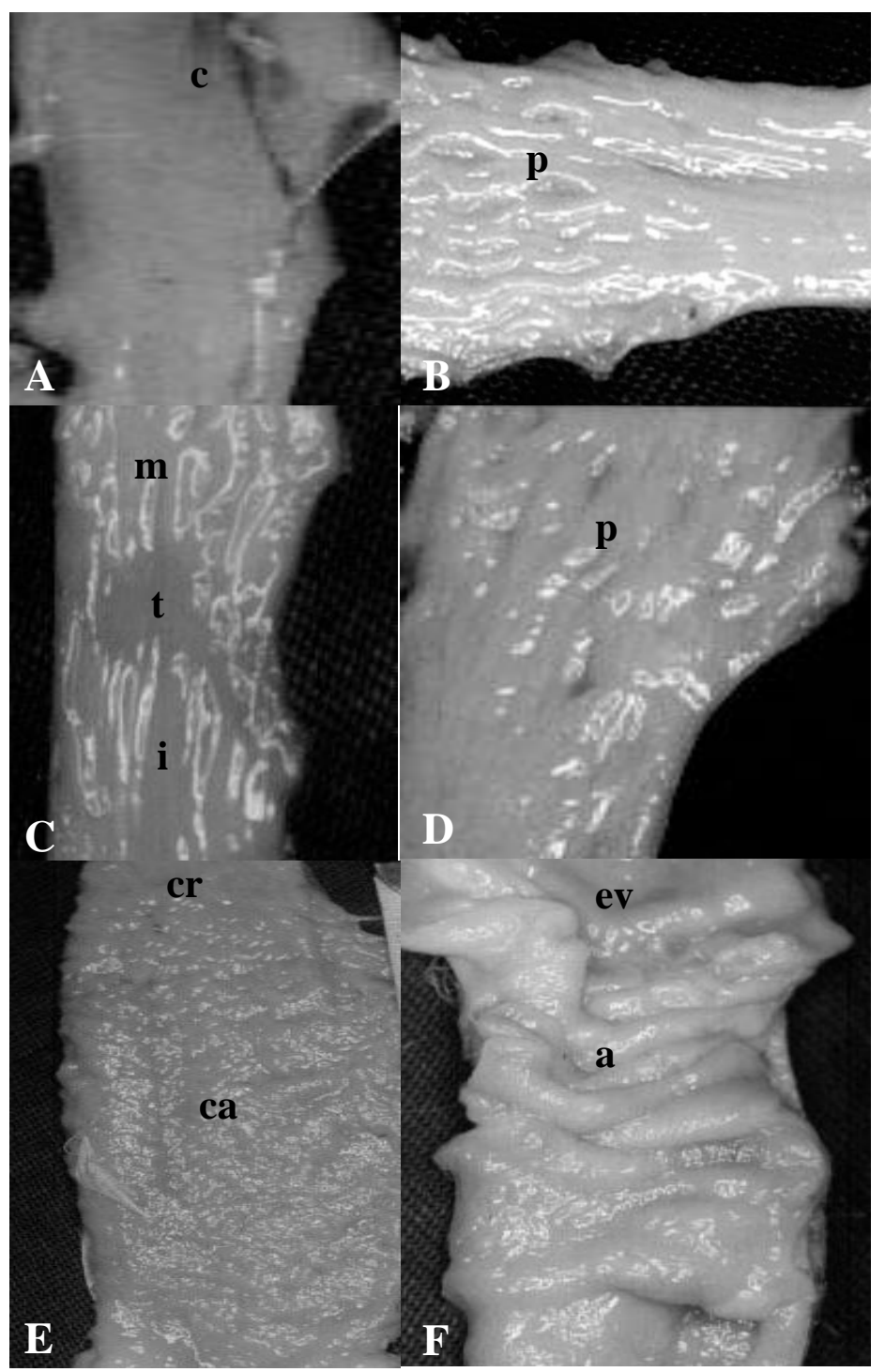

Figura 1. Morfologia do infundíbulo, magno, istmo, útero e vagina de marrecas Ana boschas evidenciando em: AMucosa da região tubular (colo) do infundíbulo com coloração rosa-pálido (c); B- Mucosa do magno com suas pregas altas e espessas (p); C- Região de transição translúcida (t) entre a mucosa do magno (m) e istmo (i); D- Mucosa do istmo com suas pregas curtas e estreitas (p); E- Mucosa da porção cranial do útero (cr) e caudal (ca) e em: FMucosa da vagina com a presença de anéis (a) e o esfíncter vaginal (ev). 


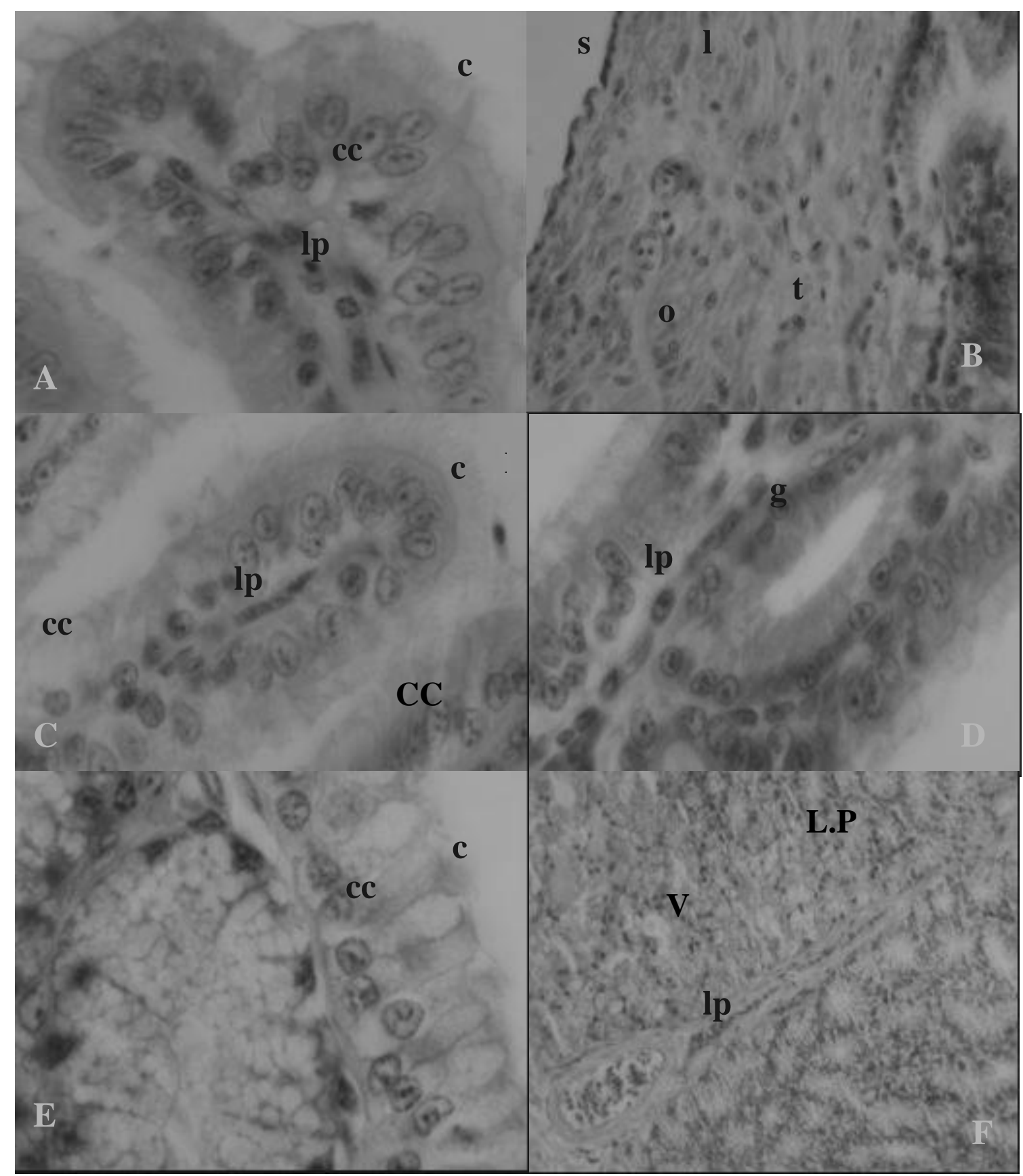

Figura 2. Fotomicrografias do infundíbulo e do magno de marreca Ana boschas. Porção cranial do infundíbulo evidenciando em: A- Mucosa revestida por epitélio pseudoestratificado cilíndrico ciliado (c), com células caliciformes, (cc) apoiado em lâmina própria (lp). H.E., 100X e em: B- Muscular com fibras musculares lisas cortadas longitudinal (l), transversal (t) e obliquamente (o) e serosa (s). H.E., 40X. Porção caudal do infundíbulo indicando em: C- Mucosa revestida por epitélio pseudoestratificado cilíndrico ciliado (c), com células caliciformes (cc), apoiado em lâmina própria (lp). H.E., 100X e em: D-Glândula tubular (g) na lâmina própria (lp). H.E., 100X. Magno mostrando em: E- Mucosa revestida por epitélio pseudoestratificado cilíndrico ciliado (c), com células caliciformes (cc). H.E., 100X e em: F-Lâmina própria (lp) com numerosas glândulas tubulares (g). H.E., 20X. 
Em relação à histologia, verificou-se que as pregas curtas da vagina estavam recobertas por epitélio pseudoestratificado cilíndrico ciliado, com células caliciformes, apoiado em lâmina própria de tecido conjuntivo frouxo, rico em tecido linfático difuso. No interior da lâmina própria desse segmento, próximo à junção ao útero, evidenciaram-se glândulas simples tubulares, revestidas por células cilíndricas, com a função de armazenar espermatozoides em seu lúmen (Fig. 3E). A camada muscular da vagina foi a mais espessa quando comparada à dos segmentos anteriores e continha fibras cortadas longitudinal, transversal e obliquamente (Fig. 3F).

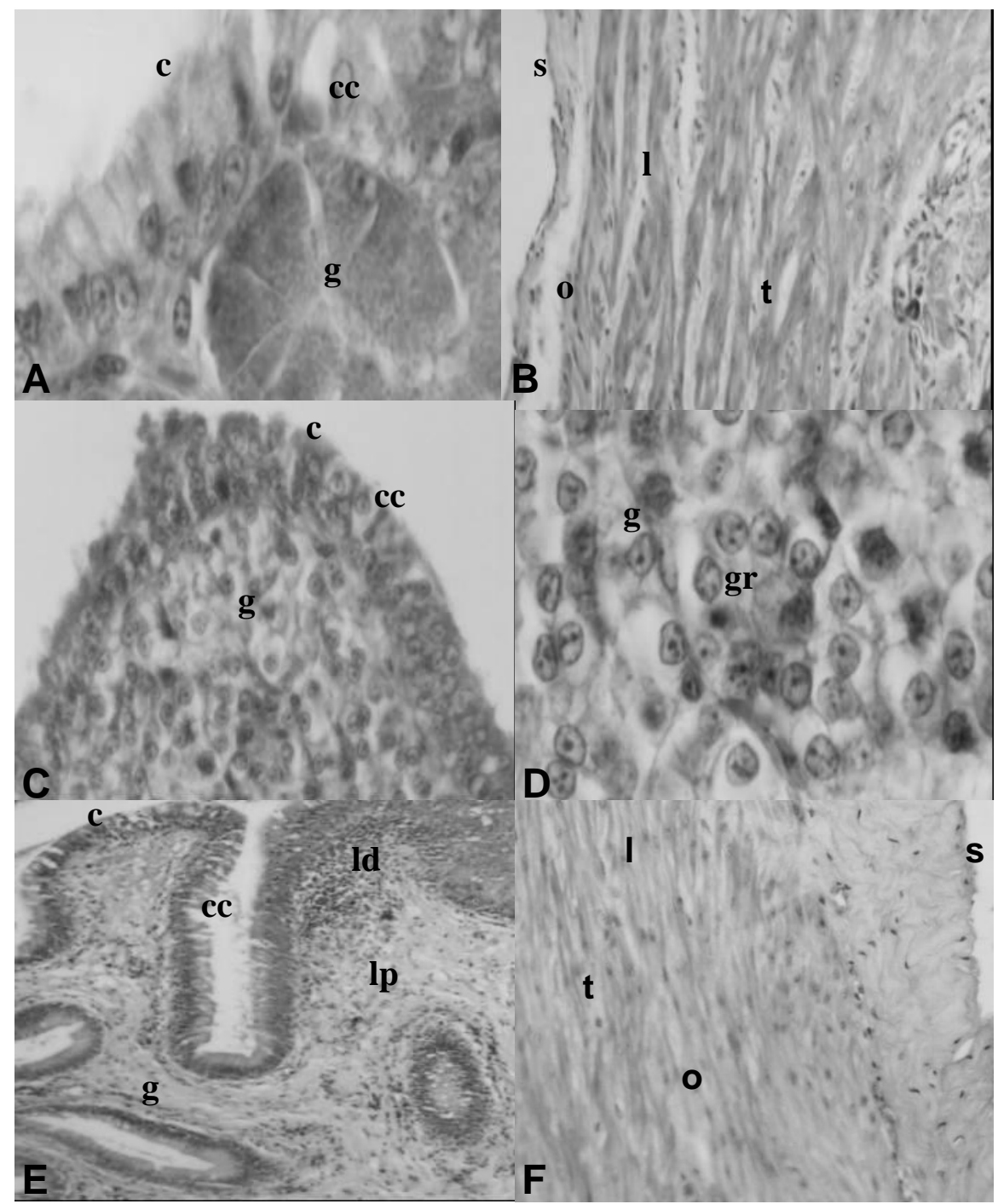

Figura 3. Fotomicrografias do istmo, útero e vagina de marreca Ana boschas. Istmo evidenciando em: A- Mucosa revestida por epitélio pseudoestratificado cilíndrico ciliado (c), com células caliciformes (cc), sustentado por uma lâmina própria com numerosas glândulas tubulares ramificadas (g). H.E., 100X e em: B- Muscular com fibras musculares lisas cortadas longitudinal (l), transversal (t) e, obliquamente (o) e serosa (s). H.E., 20X. Útero indicando em: C- Mucosa revestida por epitélio pseudoestratificado cilíndrico ciliado (c), com células caliciformes (cc), apoiado em lâmina própria com numerosas glândulas tubulares enoveladas (g). H.E., 40X e em: D- glândulas tubulares enoveladas (g) com grânulos apicais (gr) nas células glândulares. H.E., 100X. Vagina mostrando em: EMucosa revestida por epitélio pseudoestratificado cilíndrico ciliado (c), com células caliciformes (cc), e lâmina própria (lp) com tecido linfático difuso (ld) e glândulas simples tubulares (g). H.E., 10X e em: F- Muscular com fibras musculares lisas cortadas longitudinal (l), transversal (t) e obliquamente (o) e serosa (s). H.E., 20X. 


\section{DISCUSSÃO}

Este estudo revelou que o oviduto de marrecas apresentou forma tubular e estava localizado no quadrante dorsal esquerdo da cavidade abdominal. As descrições morfológicas do infundíbulo, magno, istmo, útero foram semelhantes às dos galiniformes, descritas por Nickel et al. (1977), Sisson e Grossman (1986) e Dyce (1996).

O oviduto de marrecas em postura mostrou-se maior do que o de galinhas domésticas $(50 \mathrm{~cm})$, o que permite aventar a hipótese de que o tamanho desse órgão nessas aves estava diretamente relacionado à fase reprodutiva. Este achado está em conformidade aos relatos de Nickel et al. (1977), ao narrar que, na fase de inatividade sexual, o oviduto apresenta-se pequeno e menos volumoso, enquanto, durante a fase de postura, observa-se um aumento de tamanho de todo o oviduto. Histologicamente, evidenciou-se que o oviduto de marrecas apresentou características similares às descritas para o oviduto de patas (Das e Biswal, 1968) e para o de galinhas domésticas (Banks, 1992; Bacha e Bacha, 2000), ressaltando-se a ausência de células caliciformes na porção cranial do infundíbulo das marrecas.

Morfologicamente o infundíbulo consistiu de um funil seguido por uma região tubular, estrutura semelhante à descrita por Nickel et al. (1977) em galinhas. Quando em postura, o infundíbulo de marrecas apresentou um comprimento médio de $8 \mathrm{~cm}$, enquanto o de galinhas foi de $7 \mathrm{~cm}$ (Giesberg, 1922; Romanoff e Romanoff, 1949). Este segmento estava constituído por uma região cranial (aglandular) e uma caudal (glandular), semelhantes às descrições de (Banks, 1992). Histologicamente, observou-se que o epitélio que reveste a porção cranial do infundíbulo, apresentou células caliciformes, as quais não foram verificadas nos galiniformes, destacandose a perua (Verma e Cherms, 1964) e a galinha (Banks, 1992; Bacha e Bacha, 2000). Essas células caliciformes presentes no epitélio da porção cranial podem estar relacionadas com a produção de mucina, visto que o ovo de marrecas é maior que o da galinha, o que requer maior quantidade de secreção dessas células nessa região, facilitando o seu deslizamento ao percorrer esse segmento.
O magno foi o segmento mais longo e espiralado do oviduto da marreca em postura, característica semelhante à descrita para os galiniformes (King, 1986). As glândulas tubulares foram muito numerosas nessa região, dados que confirmam os relatos de Etches (1996). São as responsáveis pela síntese de albumina, perfazendo $54 \%$ da clara do ovo. A camada mucosa do magno de marrecas apresentou-se bem espessa, semelhante às descrições de King (1986), citado por Sisson e Grassman (1986), em relação às galinhas. Possivelmente essa espessura deve-se à grande quantidade de glândulas tubulares existentes no interior das pregas da mucosa.

O comprimento médio do istmo foi de $9,25 \mathrm{~cm}$, enquanto o de galinhas foi de $8 \mathrm{~cm}$ (Giesberg, 1922; Romanoff e Romanoff, 1949). Histologicamente, este segmento mostrou pregas da mucosa estreitas e curtas que estavam revestidas por epitélio pseudoestratificado cilíndrico ciliado, com células caliciformes, apoiado em tecido conjuntivo frouxo vascularizado, com a presença de numerosas glândulas tubulares. Essa característica histológica, com alusão a essas glândulas, possibilita aventar a hipótese de que elas são as responsáveis pela formação da membrana da casca e dos $10 \%$ do albúmen. Tal hipótese respalda-se em King (1986), ao descrever que o istmo é o segmento do oviduto responsável pela formação da membrana da casca e os $10 \%$ restante do albúmen. Ainda, em relação a essas glândulas, pode-se dizer também que elas sintetizam as membranas interna e externa da casca do ovo. Esta suposição fundamenta-se nos relatos de Gilbert (1967), ao descrever que a membrana interna da casca é sintetizada assim que a gema penetra no istmo, e a membrana externa, quando o ovo começa a se deslizar neste segmento.

O útero de marrecas apresentou estrutura semelhante a um saco, com comprimento médio de $5,25 \mathrm{~cm}$, enquanto em galinha, na fase de postura, o comprimento médio foi de $8 \mathrm{~cm}$ (Dyce, 1996). Neste estudo, observou-se que o útero possui uma porção cranial curta e estreita e outra porção caudal, semelhante a uma bolsa, relato similar ao descrito por Johnston et al. (1963), pressupondo-se que essa última região tenha a função de formação da casca do ovo. Tal suposição fundamenta-se em King (1986), ao relatar que a porção caudal desse segmento é o 
local onde ocorre a formação da casca do ovo no período de 20 horas e 40 minutos. Histologicamente, o útero da marreca apresentou numerosas glândulas enoveladas com grânulos apicais no interior das células. Estas glândulas estavam na lâmina própria de tecido conjuntivo frouxo, característica que também pode ser observada em alguns galiniformes como a perua (Verma e Cherms, 1964) e a galinha (Sisson e Grossman, 1986).

A vagina de marrecas apresentou-se inclinada, constituída por oito anéis, em média, porém ausentes nos galiniformes (King, 1986; Dyce, 1996), com musculatura bem mais espessa quando comparada às dos segmentos anteriores, aspecto morfológico que pode estar relacionado à função de expulsar o ovo. Observou-se que a junção do útero à vagina foi demarcada por um esfíncter, semelhante ao que se descreve para a galinha doméstica (Sturkie, 1965).

\section{CONCLUSÃO}

O oviduto de marreca apresentou características morfológicas e histológicas distintas das descritas para os galiniformes.

\section{AGRADECIMENTO}

À Fundação de Amparo à Pesquisa do Estado de São Paulo - FAPESP, pelo auxílio financeiro fornecido para o desenvolvimento desta pesquisa.

\section{REFERÊNCIAS BIBLIOGRÁFICAS}

AITKEN, R.N.C. The oviduct. In: BELL, D.J.; FREEMAN, B.M. (Eds). Physiology and biochemistry of the domestic fowl. London: Academic, 1971. p.1237-1239.

BACHA, W.J.; BACHA, L.M. (Eds). Color atlas of veterinary histology. 2.ed. Philadelphia: Lippincott Williams \& Wilkins, 2000. 318p.

BANKS, W.J. (Ed). Histologia veterinária aplicada. 2.ed. São Paulo: Manole, 1992. 629p.

BOBR, L.W.; LORENZ, F.W.; OGASAWARA, F.X. Distribution of spermatozoa in the oviduct and fertility in domestic birds.1. Residence sites of spermatozoa in fowl oviducts. J. Reprod. Fertil., v.8, p.39-47, 1964.
DAS, L.N.; BISWAL, G. Microanatomy of the reproductive tract of domestic duck (Anas boscas). Indian Vet. J., v.45, p.1003-1009, 1968.

DYCE, K.M. Anatomia das aves. In: DYCE, K.M.; SACK, W.O.; WENSING, C.J.G. (Eds). Tratado de anatomia veterinária. 2.ed. Rio de Janeiro: Guanabara Koogan, 1996. p.631-650.

ETCHES, R.J. (Ed). Reproduction in poultry. Cambridge: University Press, 1996. p.208-233.

FUJII, S.; TAMURA, T. Location of sperms in the oviduct of the domestic fowl with special reference to storage of sperms in the vaginal gland. J. Fac. Fish. Anim. Husb., v.5, p.145-163, 1963.

GIERSBERG, H. Untersuchungen uber Physiologie und Histologie des Eileiters der Reptilien und Vogel: nebst einem Beitrag zur Fasergenese. Z. Wiss. Zool., v.120, p.1-97, 1922.

GILBERT, A.B. Formation of the egg in the domestic chicken. In: McLAREN, A. (Ed). Advances in reproductive phisiology. London: Logos, 1967. v.2, p.75-84.

GILBERT, A.B. The activity of the ovary in relation to egg production. In: FREEMAN, B.M.; LAKE, P.E. (Eds). Egg formation and production. Edinburg: British Poultry Science, 1972. v.4, p.488515.

GILBERT, A.B. Female genital organs. In: KING, A.S.; McLELLAND, J. (Eds). Form and function in birds. London: Academic, 1979. p.488-514.

HAFEZ, E.S.E. (Ed). Reprodução animal. 4.ed. São Paulo: Manole, 1988.

JOHNSTON, H.S.; AITKEN, R.N.C.; WYBURN, G.M. The fine structure of the uterus of the domestic fowl. J. Anat., v.97. p.333-344, 1963.

KING, A.S. Introdução às aves. In: SISSON, S.; GROSSMAN, J.D. (Eds). Anatomia dos animais domésticos. Rio de Janeiro: Guanabara Koogan, 1986. v.2, p.1677-1675.

NICKEL, R.; SCHUMMER, A.; SEIFERLE, E. (Eds). Anatomy of the domestic birds. Berlim: Verlag Paul Parey, 1977. p.41-50.

RIBEIRO, M.G.; TELES, M.E.O.; MARUCH, S.M.G. Estudo histológico do oviduto de Numida meleagris (Linné, 1758), com referência especial ao útero. Bios, v.2, p.43-48,1995.

ROMANOFF, A.L.; ROMANOFF, A.J. (Eds). The avian egg. New York: John Wiley \& Sons, 1949.

SICK, H. (Ed). Ornitologia brasileira. Rio de Janeiro: Nova Fronteira, 2001. 862p. 
SISSON, S.; GROSSMAN, J.D. (Eds). Anatomia dos animais domésticos. 5.ed. Rio de Janeiro: Guanabara Koogan,1986. 2000p.

STURKIE, P.D. (Ed). Avian phisiology. 2.ed. London: Bailliére, Tindall \& Cox, 1965.

SULTANA, F.; YOKOE, A.; ITO, Y. et al. The peri-albumen layer: a novel structure in the envelopes of avian egg. J. Anat., v.203, p.115-122, 2003.
VERMA, O.P.; CHERMS, F.L. Observations on the oviduct of the turkeys. Avian Dis., v.8, p.19-26, 1964.

WYBURN, G.M.; JOHNSTON, H.S.; DRAPER, M.H. The magnum of the hen's oviduct as a protein secreting organ. J. Anat., v.106, p.174, 1970. 